\title{
The role of NGOs and associations in health care for migrants in North West Morocco
}

\author{
Hayate Koubri ${ }^{1,2, *}$, Hinde Hami ${ }^{3}$, Sanou Khô Coulibaly ${ }^{1}$, Abdelmajid Soulaymani ${ }^{3}$, Nazih El Kouartey ${ }^{4}$, and Amina \\ Essolbi $^{5}$ \\ ${ }^{1}$ Faculty of Medicine and Odonto-Stomatology, University of Sciences, Techniques and Technologies, Bamako, Mali \\ ${ }^{2}$ Directorate of Population, Ministry of Health, Rabat, Morocco \\ ${ }^{3}$ Laboratory of Biology and Health, Faculty of Science, Ibn Tofail University, Kenitra, Morocco \\ ${ }^{4}$ National Agency for Health Insurance (ANAM), Rabat, Morocco \\ ${ }^{5}$ National School of Public Health (ENSP), Rabat, Morocco
}

\begin{abstract}
Associations working in the field of migrant health are currently an important link to meet the health needs of the migrant population. Draw up their inventory, in the region of Rabat-SaléKénitra, has been identified as an essential tool to analyze the roles of this category of partners, their experiences and modes of operation with a zoom on their constraints in the realization of their mission. A descriptive study, based on the literature review, interviews and focus groups with migrants, was conducted in 2018, with 25 associations active in the field of health and migration, selected by reasoned sampling; $72 \%$ of associations surveyed were created in the 2000 s. Mostly between 18 and 60 years, migrants receiving NGO's services are frequently in a situation of vulnerability and precariousness; $68 \%$ are unemployed. There are many reasons for using associations' health services, mostly by women $(56 \%)$. In a context of strong competition between the associations themselves, marked by the limits of coordination, the implementation of their health interventions for the benefit of migrants is becoming increasingly difficult. Better coordination between public authorities and associations will help to put in place efficient health interventions that meet the real needs of migrants in Morocco.
\end{abstract}

Keywords: Migrant health; NGOs; Associations; Morocco

\section{Introduction}

Migration is a heterogeneous and multifaceted phenomenon that impacts many and diverse fields, such as the economy, politics, etc. As a result, it exposes migrants to real vulnerability to health risks and a particularly high incidence of certain health problems for which the health and social systems of some countries remain ill-equipped and ill-prepared to respond to new needs. Today, more than ever, migration is a social determinant of health [1]. For that, the migrant population's health is, nowadays, receiving all the attention of the international community.

This issue of migration, as a global problem, undoubtedly requires, like any strong humanitarian and social nature phenomenon, a global approach in which Governments cannot be taken as the only parties concerned by the scourge. Thus, other stakeholders have taken the field to support and/or complement the role of international bodies and public authorities, especially since the latter had clearly shown, on many occasions, their limitations, or even their failure, facing the growing scale of migratory flows that were hitting them hard in the course of the global economic crisis, particularly on both sides of the Mediterranean. These are the non-governmental organizations and thematic associations that have been propelled to the forefront of the international migration scene due to their strategic positioning vis-à-vis the stakeholders of this humanitarian crisis that was generating victims on a daily basis, which the media transmitted, now and then, in real time, on TV and social networks. Subsequently, it seemed appropriate and even fundamental, for governments and concerned international bodies, to encourage and supervise this role that increasingly has become necessary by NGOs and associations around the migration issue [2].

Morocco, through the convergence of its public policies on migration in general and migrants' health in particular, devotes significant resources to this population and recognizes the primary role played by associations/NGOs as a strong link in meeting the needs of migrants [3], 
without however adequately responding to their health expectations. However, it remains clear that these NGOs and associations working in the field of migration play a very important role in addressing the health needs of migrants [4].

However, it is nevertheless true that the little information available on the network of associations active in Morocco in the area of migration and health, as well as the lack of quantitative data on the precise role of NGOs and associations in this field, expose us to uncertainty. Attention must therefore be paid to the development of knowledge on the role of civil society in protecting migrants' health, through the establishment of an information system and the conduct of specific studies, in particular for a better understanding of the phenomenon and, consequently, contribute to better planning of public health actions of the associations that target this vulnerable category of population. These reasons therefore fully justify the scientific legitimacy that a study on NGOs and associations working in the field of migration in Morocco has to be conducted, particularly on health issues.

With this in mind, our study was carried out under the objective of drawing up an inventory of the associations/NGOs working in the field of migrants' health in the Rabat-Salé-Kénitra region, with a focus on their roles, experiences, operation modes and on the constraints encountered in carrying out their actions, in order to draw the necessary lessons and recommendations to improve the health status of the migrant population, through better coordination of their services with those provided by the Ministry of Health.

\section{Methods}

This descriptive study took place over 4 months (April July 2018) in the Region of Rabat-Salé-Kénitra. It aims to identify interventions which come under associations in the field of migrants' health; highlight the nature of the needs expressed by migrants using the interventions of these associations; identify the characteristics of these migrants; and examine the constraints and shortcomings encountered by associations/NGOs. The aim of this research is to help find ways and means of improving the interventions of associations/NGOs and their coordination by the concerned Services.

Its first step, carried out with the officials of the Wilaya of Rabat, the Ministry of Health and the Ministry in charge of Moroccan Residents Abroad and Migration Affairs, consisted in making a preliminary selection of the most active associations in the field of health and migration. This investigation, following a reasoned sampling, made it possible to identify 30 associations active in the field of health and migration. However, only 25 associations were available and surveyed. The literature review, the questionnaires, the interviews with the heads of associations/NGOs and certain ministerial departments and the focus groups with migrants allowed to determine the nature of the health needs expressed by the latter, the diversity of the associative interventions put in place to respond to them, and the constraints experienced on the ground for their realization. In this regard, 32 people were interviewed, including 25 heads of associations/NGOs, an official at the Ministry in charge of Moroccans residents abroad and migration affairs, 5 officials at the decentralized level of the Regional Directorate of Health and an official at the level of the Wilaya of Rabat-SaléKénitra. In addition, two focus groups were carried out with some migrants who had benefited from associations/NGOs' health interventions, with the aim of defining their perception and their experience while using associations' health services.

The collected data was processed in a computerized manner using the CS Pro ${ }^{\circledR} 7.1$ Software. In addition, the qualitative analysis concerned individual interviews and focus-groups, which were transcribed in full. It was carried out initially by a vertical analysis, then a crosssectional analysis, followed by codification and thematic classification.

\section{Results}

The study revealed that $72 \%$ of the 25 surveyed associations were recently created, in the 2000s. These associations show divergences in their general characteristics. They may be generalist or specialized, set up as charitable organizations or associations of subSaharan migrants. They all carry out missions that are quite diffuse and disparate.

For the realization of their health actions, these associations mobilize diversified resources, which remain limited and do not allow the satisfaction of all the health needs of migrants. Their leaders were unanimous on the weakness of funding. They considered, for the majority, the support of the Ministry of Health "insufficient" if not "absent".

Generally, between the ages of 18 and 60, migrants receiving health services are, for the most part, in a situation of vulnerability and precariousness; their level of education is relatively high, with $41 \%$ at the higher level and $22 \%$ at the secondary level; but $68 \%$ are without professional activity. The majority are women (56\%) which most solicit associations and NGOs for health services.

Table 1. Sociodemographic profile of migrants in Morocco in 2018

\begin{tabular}{|l|l|}
\hline \multicolumn{2}{|c|}{ Morocco in 2018} \\
\hline Nationality & $\begin{array}{l}\text { The majority are from Mali, } \\
\text { Senegal, Gambia, Nigeria and } \\
\text { Ghana }\end{array}$ \\
\hline Gender & $56 \%$ women. \\
\hline Age & $\begin{array}{l}80 \% \text { aged between } 18 \text { and } 60 \text { years } \\
\text { old. }\end{array}$ \\
\hline $\begin{array}{l}\text { Level of } \\
\text { education }\end{array}$ & $41 \%$ with higher level \\
\hline Marital status & $57 \%$ single \\
\hline $\begin{array}{l}\text { Professional } \\
\text { situation }\end{array}$ & $68 \%$ without profession \\
\hline
\end{tabular}




\begin{tabular}{|l|l|}
\hline Legal status & $\begin{array}{l}45 \% \text { in illegal administrative } \\
\text { situation }\end{array}$ \\
\hline
\end{tabular}

Their reasons for seeking healthcare are similar to those observed among people in precarious situations, with comparable barriers in terms of access to care.

Fig. 1. Nature of the services requested

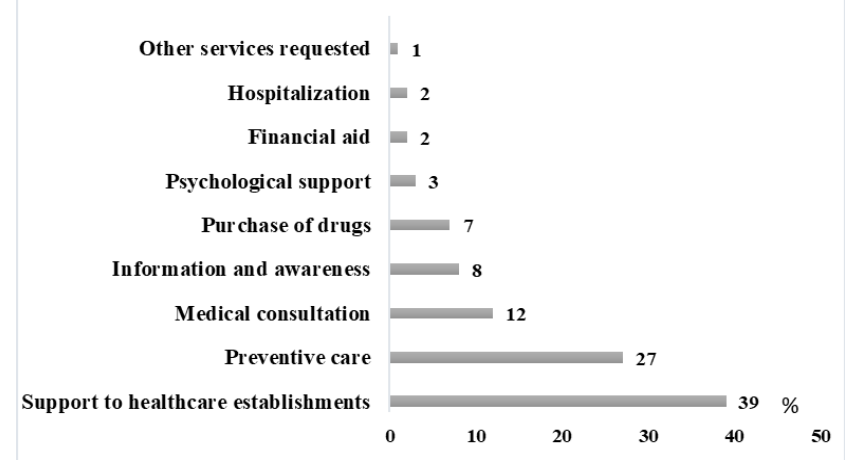

The first need expressed by migrants (39\%) was that of accompaniment to health institutions, especially to the clinics of the Ibn Sina University Hospital. According to the leaders of the associations interviewed, access to care at these hospitals is a constraint for migrants; that's why they are asking for their support. To meet the needs of migrants, $65 \%$ of associations focus their activities on preventive and curative interventions as caravans and medical campaigns.

Fig. 2. Nature of health interventions

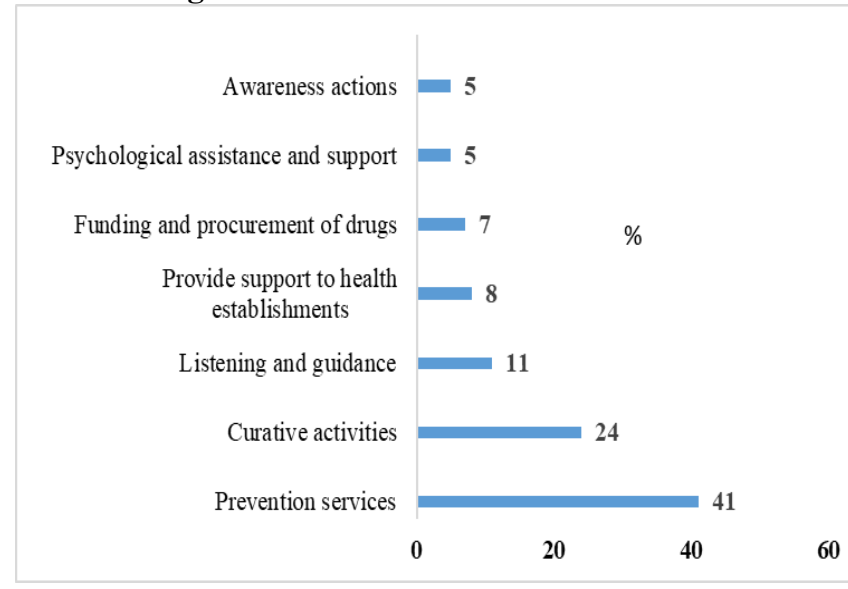

In terms of reported pathologies, STIs/AIDS are the most frequent $(50 \%)$, followed by childhood diseases $(10 \%)$, then certain chronic diseases: diabetes $(6 \%)$ and arterial hypertension (5\%).

Fig. 3. Health fields covered by associations' interventions

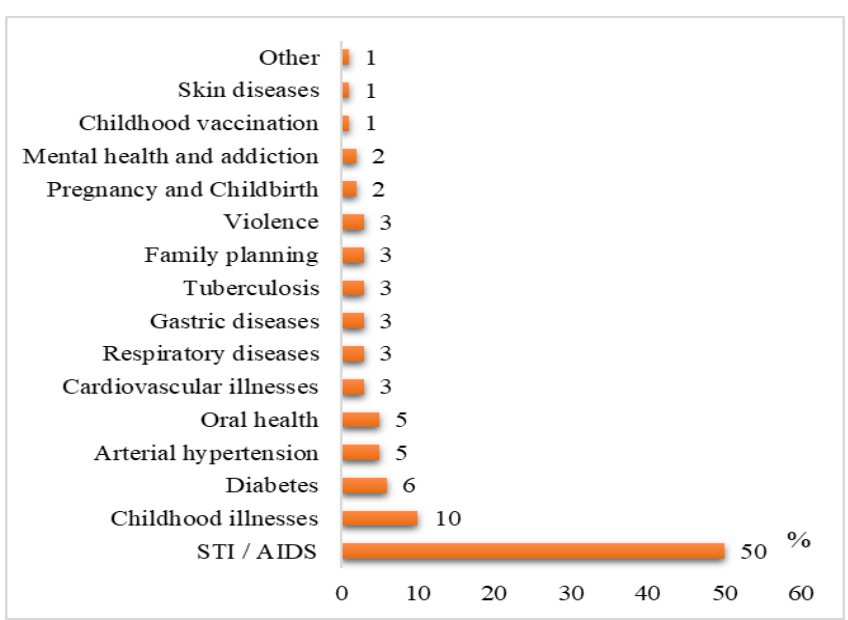

To accomplish their health mission, the associations face several difficulties, mainly relating to the modesty of the means at their disposal, both in human and material resources. At first glance, it is clear that financial problems are preponderant, although this aspect is not surprising. Indeed, the question of funding seems to be the major concern of most associations, since more than $60 \%$ of them have reported it to us.

On the other hand, the figure below shows that $48 \%$ of respondents' associations blame the lack of support on the Ministry of Health in terms of human, material and financial resources, as the main obstacle to the smooth running of their action in the field of migrants' health.

Fig. 4. Constraints related to relations with the Ministry of Health

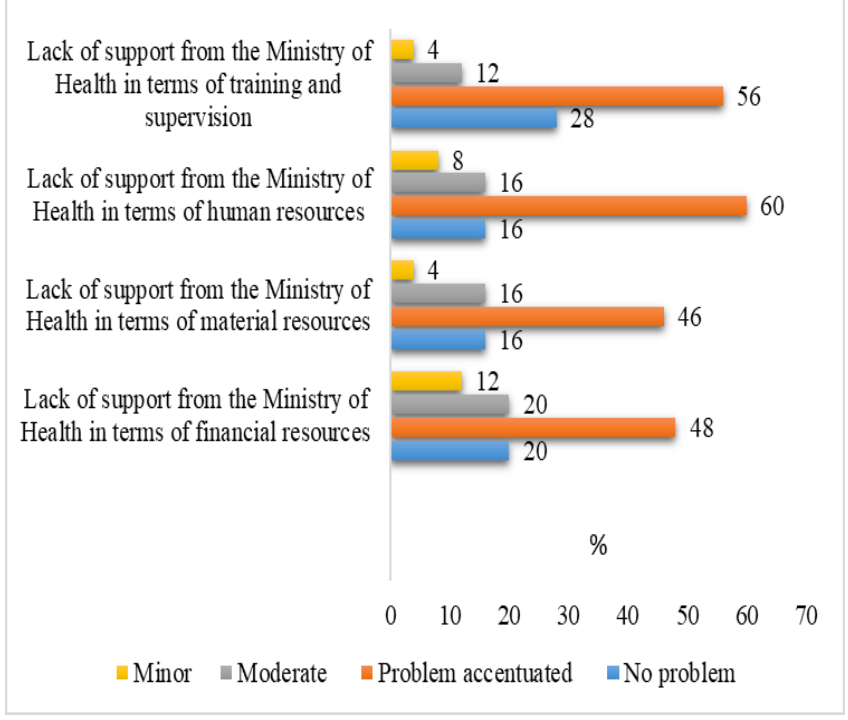

The leaders of the associations also raise problems of coordination with the Ministry of Health. Thus, $60 \%$ of associations are moderately satisfied, or even dissatisfied, with their relations with the Ministry of Health. In this sense, the migrants' familiarity lacks with the medical environment and the health actors' knowledge shortage of sociocultural determinants generate tensions between the two parties and even with mediators. This pushes migrants to resort to associations to solve their health problems. Also, the problem of discrimination was 
intensely felt everywhere, whether by sub-Saharan associative actors themselves, or by the migrants they guide or accompany.

Moreover, these officials reveal that interventions for health services are becoming increasingly difficult in a context of strong competition between the various associations themselves. They also assert limits of coordination in the implementation of their actions.

\section{Discussion}

Since the publication of the National Immigration and Asylum Strategy (SNIA) in 2013, significant efforts have been made to ensure better access for migrants, particularly sub-Saharans, to primary healthcare facilities, emergency services and assistance to pregnant women, because their state of health is a major concern of the public authorities that goes back many years. The challenge is to promote migrants' right to health without any discrimination and to ensure that health services are available, accessible and of good quality, and to put in place practices that take into account the needs of migrants as stipulated in the 2011 Constitution and recommended by the World Health Assembly held in 2008, through its resolution WHA.61.17. [5].

Long before, and apart from the Ministry of Health, some civil society actors launched, as early as 2003, several initiatives aimed at guaranteeing migrants' right of access to health services. The public authorities interviewed in most of the Kingdom's cities largely recognized the importance of associative actors; a point of view that sometimes leads to cooperation programs. NGOs and associations are seen as experts on the most persuasive issues on the ground, as well as the main awarenessraising tool for irregular migrants, as they trust them more than official bodies. They play a very important role in the social and economic development of communities and individuals alike, and are an integral part of the strategy to combat poverty. They also contribute to solving the problems of communities and individuals. However, the associative actors interviewed regret that their involvement in the implementation of the SNIA and other related projects has not been effective. Rarely consulted beforehand, and generally informed once the measures are decided, the associations have been more observers than stakeholders in this process. In view of their contributions and the place they occupy, our reflection on their interventions and their coordination will allow them to better target their actions and thus fully play their role $[6$, 7].

Thus, this research highlighted the role played by associations and NGOs in the Rabat-Salé-Kénitra region in the migrants' health care. In this sense, the results showed that most of the associations, working in the field of migration and health, were created recently in the 2000 s, i.e. $72 \%$ of the associations, $20 \%$ of which are less than 3 years old; $28 \%$ of associations were created before the 2000s.

In terms of their missions, objectives and statutes, an important point emerges from the results presented: it is the lack of clarity and precision of the missions and objectives of certain associations. The objectives remain vague and imprecisely worded. In fact, the associations in our study have both direct and indirect strategies. This finding is in line with the study carried out in 2004 by Capital Consulting [8]. Also, it follows from all the interviews and quantitative results that the associations mobilize diversified resources to be able to implement their actions in a general way and more particularly in the field of migrant health. However, these resources remain limited and do not allow all the health needs of migrants to be met. In this regard, it was noted that those responsible are unanimous on the low level of funding for associations. They consider that the contribution of international organizations, the donations of individuals and the contributions of their members are very important in the financing of their health activities for migrants [9]. Indeed, several international and national organizations and partners finance their actions through partnerships.

The conclusion that emerges from the analysis of the results is that the resources of associations and NGOs are limited and that the support of the Ministry of Health is often considered absent by the majority of associations, or insufficient for the rest. Many associations, especially sub-Saharan ones, have not used the Ministry of Health to seek its support in terms of human, material or financial resources. This is explained by the coordination's weak between these associations and the Ministry of Health [10, $11]$.

Whether they are associations born of the immigrant movement or Moroccan associations for solidarity and support for migrants, all of these organizations play an essential role and develop several activities. Their role is multiple. They are a factor of socialization and a place of resourcing of identity and play a stabilizing community role, conviviality and mutual aid, a role of creation of social capital, participation through partnerships established with public and private actors, politicians and trade unions, etc. This is affirmed by Cattacin (2007) [12, 13].

The associations interviewed also include their actions in the national effort to combat poverty and exclusion, preserve the environment and integrate women into development. They also aim to support poor populations (vulnerable women, abandoned or exploited children...), strengthen social ties, etc.

This research highlighted the diversity of actions carried out by these associations in the field of health. They carry out a very diverse mission: information, reception, mutual aid, support for the people concerned, public awareness, training of patients, families and professionals, development and management of social programs, therapeutic education, research activities, advocacy, partnership actions, accompaniment to health institutions, translation/reformulation of the doctor's words by the social worker... This supports what was reported by the study [14].

In this respect, the prevention actions implemented by the associations that contributed to this study are carried out as workshops, focus-groups or awareness-raising campaigns through the distribution of information materials. They take place within the associative structures, or on the premises of the partners [15]. 
In terms of advocacy, these associations are often involved in networks. The supervision provided by certain networks such as the "EuroMed" platform allows these associations to benefit from training sessions and to be regularly involved in debates directly or indirectly related to the migration issue (human rights, local development, Euro-Mediterranean partnership, etc.).

Nevertheless, despite the efforts made by these organizations, migrants' access to secondary, tertiary and mental health services remains difficult for many of them because of the lack of resources for the purchase of medicines and the payment of hospitalizations and biological or radiological examinations, and the complexity of administrative measures and procedures. Thus, the success of their interventions is effective when they are more developed at the organizational level and work in partnership with other organizations, foundations or with the government and have sufficient resources. This result corroborates the result of the study [16, 17]. In this sense, the 20 migrants who participated in focus groups as part of this study raised several problems of access to healthcare, experienced daily, which prompted them to turn to associations to benefit from their support and accompaniment. They spoke of the linguistic communication difficulties, generally recognized as a barrier to access to healthcare. To this difficulty is often added the problem of the caregiver-patient relationship, sometimes marred by attitudes of rejection or discrimination. Legal or administrative obstacles also push immigrants, especially in irregular administrative situation, to request the intervention of associations and NGOs to facilitate their access to health establishments. In addition, they raised the issue of medical costs, as they are excluded from the basic medical coverage system. This is why they are asking for financial support to buy the drugs or to benefit from the analyzes and radiological examinations prescribed. All these barriers would seriously obstruct migrants' access to the health system in the absence of the support of associations. Several studies corroborate the above and evoke the same reasons which push vulnerable migrants to resort to NGOs and associations [18]. It is mainly women (56\%) who ask associations and NGOs for guidance or support in order to benefit from maternal and child healthcare (monitoring of pregnancies, vaccinations), care relating to mental health, care for children, chronic diseases, psychological support, medical consultations, legal and social support, and preventive care.

On the other hand, the cross-analysis of the results of the interviews carried out with those of the questionnaires shows that the migrants who have benefited from the associations' interventions are between 18 and 60 years old, and come from some forty African States. The majority of them, according to the associations' statements, are from Congo Brazzaville, Senegal, Gambia, Nigeria, Guinea, and Côte d'Ivoire. This supports what was reported by the study of the International Federation of Red Cross and Red Crescent Societies in 2010. $45 \%$ of them are in an irregular administrative situation, and $41 \%$ are in a regular situation.
In addition, their level of education is relatively high, $41 \%$ of migrants have a higher level, and $22 \%$ are at the secondary level. This, according to several studies, can be considered as an opportunity for the host country to integrate them into the various development projects, especially since $68 \%$ of them are without profession [ 19 , 20].

In terms of pathologies and conditions reported by migrants who benefited from associations and NGOs' interventions, the results of the focus groups generally corroborate those of the questionnaires. Thus, the majority of associations [23] observe with their users a similarity of recurrent pathologies (STI, HIV/AIDS, psychological and psychiatric suffering, childhood diseases, digestive problems, oral health...) with any other person living in precarious situations and experiencing comparable obstacles to access to care.

In addition, chronic diseases and conditions such as diabetes, respiratory diseases, high blood pressure, cardiovascular diseases, health problems resulting from difficult living and working conditions, as well as unhealthy lifestyles pose serious and frequent health problems among irregular migrants. In addition, the latter can develop serious chronic diseases because they do not have adequate access to preventive health services.

Indeed, a research has shown the preponderance of the reporting of STIs/AIDS (50\%), followed by childhood diseases $(10 \%)$ and some chronic diseases such as diabetes $(6 \%)$ and hypertension (5\%). A survey supports this finding and suggests that one third of irregular migrants who come for a consultation claim to suffer from one or more chronic diseases. The number of chronic diseases tends to increase with age, especially for the Syrian migrants [21, 22].

In another sense, the experience highlighted that the various associations spend a considerable part of their funds to finance the interventions related to the health of migrants, mentioned above. In view of the means at their disposal and the nature of the situations in which they get involved, the role of these bodies sometimes oscillates between medical care actions, awareness-raising and guidance actions and mediation actions with the aim of helping to access health institutions due to the lack of a universal health coverage system. The importance of their contribution is obvious, but it must be borne in mind that small associations often have difficulties in setting up activities that will solve the health problems expressed by migrants. This result is in line with that reported in MCMREAM [23].

In addition, the results of this study revealed that the first difficulty encountered by the associations comes from the modesty of the means at their disposal to ensure the daily functioning, both in terms of material and human resources. According to the results of the study, the financing of international bodies is the mean most used by associations $(60 \%)$, followed by donations $(20 \%)$, which shows that these structures are highly dependent on contributions from international bodies. Public subsidies are granted to implement specific actions (project, workshop, training, etc.). They do not make it possible to cover all the costs of the associations. In this sense, the results of our interviews are generally in line with the 
results collected by the questionnaires and with other studies carried out at international level [23].

It follows that the great challenge to the proper development of the above-mentioned actions is the inadequacy of financial, but also human resources, which has a direct impact on the projects of NGOs/associations, and thus on their relations with migrants, which poses real difficulties in meeting all the needs expressed by the migrant population. The latter faces significant obstacles when trying to access health services, even in case of emergency, in the absence of regulations on the financing of the care of irregular migrants. This supports the results of a study conducted by "Médecins du Monde" in 11 countries in 2009.

At the same time, the interviews' results reveal that the NGOs' work is difficult in a context of strong competition between the various associations facing the communities of origin, in terms of members, and deal with local authorities, in terms of support. The intervention of multiple associative actors and community agents, in the absence or lack of well adapted coordination and governance instruments to the context of migration and the nature of the stakeholders, creates serious difficulties for associations and even sick migrants. This observation has been mentioned in some studies [23, 24]. In order to overcome this disadvantage, the leaders of the associations suggest that the tools of partnership, coordination and networking be developed and strengthened with the implementation of a framework of synergy between all stakeholders. This supports what was reported by Dauvrin's study in 2010 [25].

In addition, interviews with NGOs and migrants have identified a number of obstacles to their access to medical care, which leads them to contact associations. The main obstacles to access to health care remain within language and cultural barriers for the majority of the migrant population, regardless of their residence status in Moroccan territory. Thus, migrants request the intervention of associative mediators considered essential. Our findings are in line with those of several authors who affirm that associations play a role of coordination and mediation, as contact point between migrants and other institutions $[25,26]$.

Interviewees and migrants who participated in the focus groups reported that the causes behind their conflicts with health professionals are related to several factors. These results are affirmed by those of the Maillet studies [27, 28].

In terms of the effectiveness of coordination, and as mentioned by some interviewed officials, collaborations and coordination between associations and different actors in the field of migrant health exist, but are not formalized or effective as is desirable. Many collaborations have been set up with several stakeholders within the framework of specific projects or specific actions. However, they are still insufficient.

In view of the above-mentioned findings, the leaders of the associations agree to highlight several needs and interests in many areas. The need for support, training, professionalization, and capacity building is important for the majority of interviewees. This is affirmed by Schaer's study $[29,30]$.
On the other hand, and to face healthcare barriers at the level of health institutions, the leaders of the associations and the migrants who participated in the focus groups suggest actions that raise health and social professionals' awareness, including the basic curricula regarding the health of migrants and their needs. The associations' relations with health professionals must evolve into a clear and good quality partnership. In a large number of cases, noting the magnitude of the task, no category of professionals can claim the position to provide a comprehensive and sufficient response to the requests of associations and migrants requesting services $[1,31]$.

Also, our interviewees recommend the integration of interpreters, and also insist on the training/recruitment of caregivers able to speak different languages. This requires, beforehand, strengthened teamwork and coordination at all levels of the health system [24, 32].

On the other hand, effective cooperation between public authorities and associations/NGOs can also make it possible to implement coherent and effective interventions for the benefit of migrants.

As a synthesis, we were able to note the growing importance taken by the issue of "migration and health" and the sustained interest of the associations in this issue; this interest is manifested by the diversity of interventions and actions at several levels: advocacy, awareness raising, service delivery... It is clear that this dynamism of the associative network is a great achievement for civil society.

\section{Conclusion}

In an issue as complex as the management of the migrants' health by associations, it is not easy at present to have an overview of the situation in Morocco; although our study has drawn up a broad inventory of the situation in the region of Rabat-Salé-Kénitra. Indeed, our results confirm both the interest and the complexity of the study of the associations' role in the healthcare of the migrants, articulated in the social field. It is possible that a study at the national level could provide other insights that would serve to better understand the problem. This work of harvesting and analysis therefore remains to be enriched by other studies related to the context of each region, in particular the development of a National Mapping of the different stakeholders.

The second lesson of this research is that we must not restrict the scope of health and social associations to the tip of the iceberg. There persists a nebula of small associations with a sometimes obscure role and very fragmented visibility. But these associations play a fundamental role of social link, local remedies, accessibility of care and services physically and psychologically... Finding and studying them is often an obstacle course; a process described by many migrants who one day face a health problem and go door to door in search of information, solutions and support.

Better coordination between public authorities and associations/NGOs will certainly help to put in place efficient health interventions that meet the real needs of migrants in Morocco. 


\section{Acknowledgements}

The authors would like to thank the officials of the Wilaya of Rabat-Salé-Kénitra, the officials of the Ministry in charge of Moroccan Residents Abroad and Migration Affairs. They also thank the officials and executives of the various associations and NGOs met. They also thank the library managers of the National School of Public Health of Morocco.

They also thank the International Organization for Migration, the United Nations High Commissioner for Refugees in Rabat and all the people from Ministry of Health who, through their commitment, contributed to the realization of this study.

\section{References}

1. Organisation Internationale pour les Migrations. World Migration (Report, 2018)

2. M. Alioua, Hommes et migrations, 1303, 139-145 (2013)

3. ORMES. Guide des associations ouvrant dans le domaine de la migration au Maroc (2016)

4. https://www.migrationssante.org (accessed March 22, 2018)

5. MCMREAM, Politique nationale d'Immigration et d'Asile (Report, 2017)

6. P. Collerette, M. Roy, Pouvoir leadership et autorité dans les organisations, Hors collection, 242p. (1991)

7. MCMREAM, Guide des associations cuvrant dans le domaine de l'immigration (2016)

8. Capital Consulting, Cartographie et analyse des actions sur la thématique. Migrations et Développement au Maroc ces dix dernières années (Report, 2015)

9. Ministère du Développement Social, de la Famille et de la Solidarité \& UNFPA, Guide de l'Associatif : guide pratique d'information des associations (2006)

10. Mairie de la Ville de Pontarlier. Vers une nouvelle charte de la vie associative. Questionnaire sur votre association et ses activités (2016)

11. V.C. Rueda, I. Obadiarou, État des lieux des associations de migrants des cantons de Genève et Vaud (2012)

12. S. Cattacin, M. La Barba, Migration et Association; la vie associative des migrants- une exploration de leur rôle et développement en Europe occidentale (2007)

13. M. Khachani, Le tissu associatif et le traitement de la question migratoire (Report, 2010)

14. S. Cattacin, M. Chimienti, M. Hachimi, A. Nacu, Politique de migration et politique de santé en Europe. Des normes aux pratiques (2009)

15. Plateforme Nationale Protection des Migrants. État des lieux de l'accès aux services pour les personnes migrantes au Maroc : Bilan, perspectives et recommandations de la société civile (Report, 2017)

16. E. d'Halluin, A.-C. Hoyez, Humanitaire. Enjeux, pratiques, débats, 33, 1-8 (2012)

17. FRA - European Union Agency for Fundamental Rights, Migrants in an irregular situation: access to healthcare in 10 European Union Member States (Report, 2012)

18. Agence des droits fondamentaux de l'Union européenne, FRA, Les droits fondamentaux : défis et réussites en 2012, 348p. (Report, 2013)

19. IOM, Promotion de la santé et du bien-être parmi les migrants en Égypte, Libye, Maroc, Tunisie et Yémen Mai 2015 - Octobre 2017 (Project, 2017)

20. J. Derron, Accès aux soins des populations vulnérables en Suisse. Situation et recommandations 2014 (2014)

21. H. Alami Machichi, M. Benradi, M. Khachani, M. M'ghari, A. Zekri, De l'Afrique Subsaharienne au Maroc : les Réalités de la Migration Irrégulière (2008)

22. D. Mechali, Revue Européenne des Migrations Internationales, 6-3, 99-127 (1990)

23. MCMREAM, Guide des associations ouvrant dans le domaine de l'immigration (2016)

24. L. Ruggia, Bioethica Forum, 9 (4), 143-149 (2016)

25. L. Badaoui, G. Dabo, R. Bensghir, M. Sodqi, L. Marih, A. Chakib, K. Marhoum El filali, Médecine et maladies infectieuses, 44 (6S), 62p. (2014)

26. M. Dauvrin, Santé conjuguée, 51, 19-25 (2010)

27. ORIV, Discriminations dans le champ de la santé : comprendre, prévenir, agir pour plus d'égalité, in Proceedings of January 20, 2017, Strasbourg, France

28. L. Maillet, L'adaptation des services de santé à l'égard de personnes migrants : cas des services infirmiers en première ligne (Thesis, 2014)

29. M. Schaer, D. Efionayi-Mäder, « La migration : opportunités et défis » : Conférence annuelle 2007 de la Division politique IV. Synthèse et pistes de réflexions (Report, 2007)

30. A. Mathieu, Prise en charge des patients migrants en médecine générale (Thesis, 2011)

31. B. Sanou, M. Beaudoin, J. Ngouabé, L. Lamothe, Étude des besoins de santé des immigrants francophones de Sudbury (Report, 2014)

32. T. France, M. Lahlou, Migrations irrégulières transméditerranéennes et relations Maroc - Union européenne, in Proceedings of XXVe Congrès international de la population, 18-23 July 2005, Tours, France 